\title{
A Cutaneous False Positive in Radioiodine Scintigraphy for Metastatic Thyroid Cancer
}

\author{
Elizabeth A McAninch, ${ }^{1}$ Rossana M Calderon² and Atil Y Kargi² \\ 1. Division of Endocrinology and Metabolism, Rush University Medical Center, Chicago, Illinois, US; 2. Division of Endocrinology, Diabetes and Metabolism, \\ University of Miami Miller School of Medicine, Miami, Florida, US
}

\begin{abstract}
Contamination of external sites with secretions or excretory products can mimic metastases and yield false positives in radioiodine whole-body scintigraphy for thyroid cancer. We present a case of a 26-year-old woman with differentiated papillary thyroid carcinoma who received radioiodine 131 (I-131) for treatment of persistent upper mediastinal metastasis. Her post-treatment whole-body scintigraphy revealed an unexpected focus of increased uptake near the scalp in addition to the mediastinal lesion. Although the scalp is the most common site of cutaneous thyroid cancer metastasis, differentiated thyroid cancers rarely manifest with cutaneous thyroid cancer metastasis and thus it is prudent to consider etiologies of false positive I-131 uptake in such cases. Contamination of our patient's hair from salivary secretions was confirmed on history and with coiffure repositioning during whole-body scintigraphy.
\end{abstract}

\section{Keywords}

Thyroid cancer, thyroid scintigraphy, radioiodine, whole-body scan, cutaneous metastasis, I-131, false positive

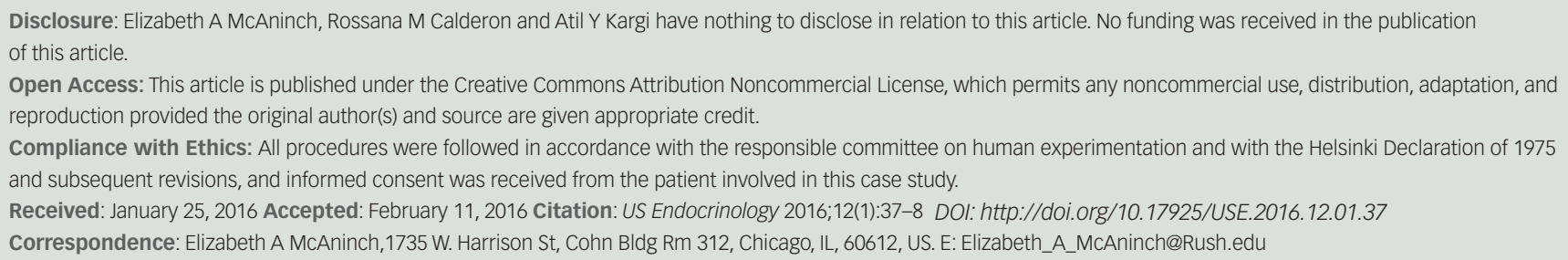

\section{Case presentation}

A 26-year-old woman with differentiated papillary thyroid carcinoma received $192 \mathrm{mCi}$ of radioiodine 131 (I-131) under recombinant thyroidstimulating hormone (TSH) treatment for persistent upper mediastinal metastasis. Radioiodine whole-body scintigraphy (WBS) was performed nine days later and showed targeting of the I-131 at the mediastinal metastasis, but also demonstrated an additional focus of significantly increased uptake near the scalp (see Figure 1). Repositioning of her coiffure by the nuclear medicine technologist revealed the source of uptake to be the hair; there was also slightly increased uptake at the fingertips. Further history was later obtained from the patient and revealed a hair-sucking habit.

\section{Discussion}

Cutaneous metastases are a rare manifestation of differentiated thyroid carcinomas ${ }^{1}$ and typically signify advanced disease with poor prognosis. ${ }^{2-4}$ When present, the scalp is the most common site of cutaneous thyroid cancer metastases. ${ }^{2,-7}$ Such lesions are usually evident on physical exam as erythematous, purple, or non-pigmented plaques or nodules, ${ }^{2-5,7}$ but can also mimic other dermatologic conditions such as topical infections, benign cysts, alopecia, or other cutaneous malignant neoplasms. ${ }^{8}$ In this case, the mobility of the high-uptake focus upon hair repositioning and the additional historical details established the false-positive nature of the I-131 uptake. If the source had not been clearly elucidated by repositioning, fusion single-photon emission computed tomography/ computed tomography imaging could have been utilized for improved localization and characterization of the focus. ${ }^{9}$

Physiologic I-131 uptake can be visualized in:

- tissues that concentrate iodine, e.g., tissues expressing the sodiumiodide symporter which include the thyroid (or ectopic thyroid tissue), salivary and mammary glands, bowel, lung, and nasal mucosa;

- tissues where thyroid hormones and thyroglobulin are degraded, i.e., the liver; or

- in radioiodine excretory products including urine, feces, saliva, and sweat. 10,11

Also, there can be increased I-131 uptake at sites of unrelated pathologic processes, including:

- inflammation or trauma, as a result of increased blood flow and capillary permeability; or

- other benign or malignant tumors, typically due to functional sodium-iodide symporter expression. ${ }^{11}$ 


\section{Figure 1: Whole-body scintigraphy after radioiodine 131 treatment for thyroid cancer metastasis reveals strong uptake near the scalp}

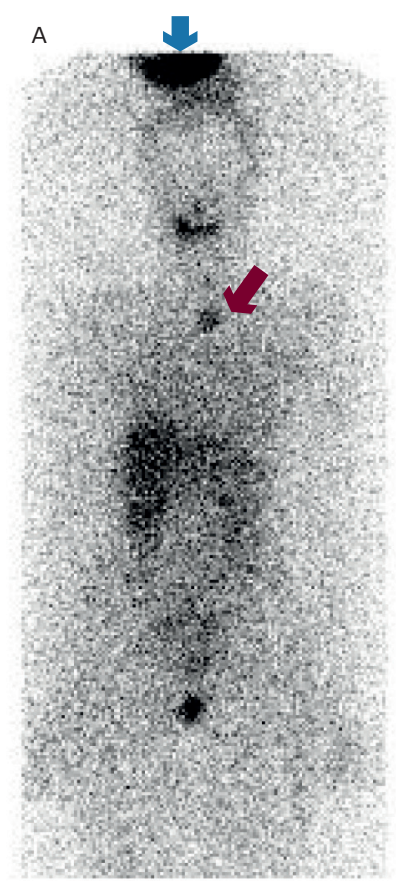

Contamination of external sites with secretions or excretory products can mimic metastases and yield false positives at a rate of $0.3 \%$ in the head and neck. ${ }^{12}$

\section{Conclusion}

As illustrated in this case, a focus of increased I-131 uptake at a site rarely associated with metastases from differentiated thyroid cancer should prompt consideration of alternate etiology, such as contamination from secretory or excretory products. Accurate interpretation of this I-131 WBS was aided by the repositioning technique employed by the nuclear medicine technologist; such strategy may prevent unnecessary workup for metastases in other cases.
1. Koller EA, Tourtelot JB, Pak HS, et al., Papillary and follicular thyroid carcinoma metastatic to the skin: a case report and review of the literature, Thyroid, 1998;8:1045-50.

2. Dahl PR, Brodland DG, Goellner JR, Hay ID, Thyroid carcinoma metastatic to the skin: a cutaneous manifestation of a widely disseminated malignancy, J Am Acad Dermatol, 1997:36:531-7.

3. Avram AM, Gielczyk R, Su L, Vine AK, Sisson JC, Choroidal and skin metastases from papillary thyroid cancer: case and a review of the literature, J Clin Endocrinol Metab, 2004;89:53037.

4. Makris A, Goepel JR, Cutaneous metastases from a papillary thyroid carcinoma, Br J Dermatol, 1996:135:860-1.
5. Alwaheeb S, Ghazarian D, Boerner SL, Asa SL, Cutaneous manifestations of thyroid cancer: a report of four cases and review of the literature, J Clin Pathol, 2004;57:435-8.

6. Horiguchi $\mathrm{Y}$, Takahashi $\mathrm{C}$, Imamura $\mathrm{S}$, Cutaneous metastasis from papillary carcinoma of the thyroid gland. Report of two cases, J Am Acad Dermatol, 1984:10:988-92.

7. Aghasi MR, Valizadeh N, Soltani S, A 64 year-old female with scalp metastasis of papillary thyroid cancer, Indian J Endocrino Metab, 2011;15:S136-7.

8. Cohen PR, Metastatic papillary thyroid carcinoma to the nose: report and review of cutaneous metastases of papillary thyroid cancer, Dermatol Pract Concept 2015:5:7-11.
9. Avram AM, Radioiodine scintigraphy with SPECT/CT: an important diagnostic tool for thyroid cancer staging and risk stratification, J NuCl Med, 2012:53:754-64.

10. Carlisle MR, LU C, McDougall IR, The interpretation of 131 I scans in the evaluation of thyroid cancer, with an emphasis on false positive findings, Nucl Med Commun, 2003:24:715-35.

11. Oh JR, Ahn BC, False-positive uptake on radioiodine whole-body scintigraphy: physiologic and pathologic variants unrelated to thyroid cancer, Am I NuCl Med Mol Imaging, 2012;2:362-85.

12. Bakheet SM, Hammami MM, Powe J, Larsson S, Radioiodine uptake in the head and neck, Endocr Pract, 2000;6:37-41. 